\title{
Inspiratory neural drive response to hypoxia adequately estimates peripheral chemosensitivity in OSAHS patients
}

\author{
F. García-Río, J.M. Pino, T. Ramirez, D. Alvaro, A. Alonso, C. Villasante, J. Villamor
}

Inspiratory neural drive response to hypoxia adequately estimates peripheral chemosensitivity in OSAHS patients. F. García-Río, J.M. Pino, T. Ramirez, D. Alvaro, A. Alonso, C. Villasante, J. Villamor. (C) ERS Journals Ltd 2002.

ABSTRACT: The aim of the present study was to examine the relationships between the responses to progressive isocapnic hypoxia and hypoxic withdrawal test in patients with obstructive sleep apnoea-hypopnoea syndrome (OSAHS) and to analyse the determinants of carotid body sensitivity in OSAHS.

Nineteen consecutive OSAHS patients and 13 healthy subjects were selected. Ventilatory $\left(\Delta V^{\prime} \mathrm{I} / \mathrm{S}_{\mathrm{a}}, \mathrm{O}_{2} / \mathrm{BSA}\right)$ and inspiratory neural drive $\left(\Delta \mathrm{P}_{0.1} / S_{\mathrm{a}}, \mathrm{O}_{2}\right)$ responses to progressive isocapnic hypoxia were determined. Peripheral chemosensitivity was evaluated by the hypoxic withdrawal test, which measures the decrease in ventilation caused by two breaths of $100 \%$ oxygen $\left(\% \Delta V^{\prime} I\right)$.

Withdrawal response and ventilatory and inspiratory neural drive responses to hypoxia were lower in OSAHS patients than in control subjects. In patients with OSAHS, $\% \Delta V^{\prime}$ I correlated significantly with $\Delta V^{\prime} \mathrm{I} / \mathrm{S}_{\mathrm{a}}, \mathrm{O}_{2} / \mathrm{BSA}$ and with $\Delta P 0.1 / S_{\mathrm{a}}, \mathrm{O}_{2}$. On stepwise multiple linear regression analysis, a strong correlation between $\% \Delta V^{\prime} \mathrm{I}$ and $\Delta P 0.1 / S_{\mathrm{a}}, \mathrm{O}_{2}$ was found. Moreover, $\% \Delta V^{\prime} \mathrm{I}, \Delta V^{\prime} \mathrm{I} / \mathrm{S}_{\mathrm{a}}, \mathrm{O}_{2} / \mathrm{BSA}$ and $\Delta P 0.1 / S_{\mathrm{a}}, \mathrm{O}_{2}$ were significantly correlated with minimum arterial oxygen saturation and with arousal index.

Obstructive sleep apnoea-hypopnoea syndrome patients have a strong relationship between peripheral chemosensitivity and respiratory response to hypoxia, suggesting that hypoxic stimulation of central chemoreceptors is minimally relevant in obstructive sleep apnoea-hypopnoea syndrome. Moreover, sensitivity of the carotid body in patients with obstructive sleep apnoea-hypopnoea syndrome is related to sleep disruption and to nocturnal hypoxia.

Eur Respir J 2002; 20: 724-732.
Servicio de Neumología, Hospital Universitario La Paz, Madrid, Spain.

Correspondence: F. García-Río

Alfredo Marqueríe 11 , izqda, $1^{\circ} \mathrm{A}$

28034 Madrid

Spain

Fax: 34917277096

E-mail: fgr01m@jazzfree.com

Keywords: Carotid body

chemosensitivity

hypoxia

sleep apnoea

\section{Received: June 12001}

Accepted after revision: April 112002

This study was supported by FIS (96/ 1280 and 99/0252) and Neumomadrid (2000) Grants.
The study of peripheral chemosensitivity in patients with obstructive sleep apnoea-hypopnea syndrome (OSAHS) has been of considerable interest over several years [1-7]. The peripheral chemoreflexes are an important mechanism for regulation of both breathing and autonomic cardiovascular function [8]. In fact, abnormalities in chemoreflex mechanisms have been implicated in the increased cardiovascular stress in patients with OSAHS. The relationship between peripheral chemosensitivity and blood pressure profile suggests that recurrent obstructive apnoeas may reset the peripheral chemoreceptor output to a higher level, causing a chronic increase in sympathetic tone and initiating hypertension $[9,10]$. Intersubject variation of heart rate changes during sleep apnoea could also be due to variations in response to hypoxia [11].

In spite of these pathophysiological implications, the role of peripheral chemoreception in OSAHS has not been adequately evaluated. The nature of the respiratory response to chemical stimuli in awake patients with OSAHS is still unclear. In these patients, depression of peripheral chemosensitivity has been reported [7]. In contrast, other investigators have concluded that response to hypoxia in OSAHS patients is normal [2-6] or increased [1].

These discrepancies in findings concerning chemical sensitivity in OSAHS could be due in part to confounding factors, such as obesity, age, sex, smoking habit, metabolic acidosis, hypercapnia, resting metabolic rate, alcohol abuse and genetic factors [12-15]. But the stimulation method employed in each study also seems to be responsible for some differences. The best established techniques for assessment of hypoxic response are progressive isocapnic hypoxic stimulation [16] and the hypoxic withdrawal test [17]. It has been demonstrated that progressive hypoxia does not adequately evaluate chemosensitivity of the carotid body because it stimulates peripheral and central chemoreceptors together [8]. Since the time required for central nervous system stimulation is considered to be about $20 \mathrm{~s}$ [18], the hypoxic withdrawal test eliminates peripheral chemoreceptor activity but leaves the humoral environment of the central respiratory system unchanged [17].

The aim of this study was to evaluate the relationship between responses to progressive isocapnic 
hypoxia and the hypoxic withdrawal test in OSAHS patients. The determinants of carotid body sensitivity in patients with OSAHS were also studied.

\section{Materials and methods}

\section{Study subjects}

Nineteen consecutive OSAHS patients and 13 healthy subjects were selected to be studied. Patients were excluded from the study for the following reasons: unwillingness or inability to perform the testing procedure; obstructive or restrictive lung disease demonstrated by pulmonary function testing; known valvular heart disease; current drug or mechanical treatment for sleep apnoea; known neuromuscular disease; abnormal thyroid function; morbid obesity (body weight $>150 \%$ ideal); and recent $(<3$ months) myocardial infarction or cerebrovascular accident. Control subjects were judged healthy by history, physical examination, electrocardiogram (ECG), spirometry and chest radiography.

Subjects were asked not to eat for $4 \mathrm{~h}$ before the study and they were also asked to refrain from using coffee, tea and alcohol for $\geqslant 12 \mathrm{~h}$, and tobacco for $\geqslant 2 \mathrm{~h}$ before each study. The study was approved by the Institutional Ethics Committee at the hospital. All subjects gave their written informed consent prior to enrolment.

\section{Methods}

Polysomnography. Healthy subjects and OSAHS patients underwent polysomnography from 23:00-07:00 h. Electroencephalogram (C3-A2, C4-A1), electrooculogram, chin electromyogram, electromyograms of the tibialis anterior of both legs, and ECG were continuously recorded. Breathing was monitored using nasal cannulas, oronasal thermistors and thoracoabdominal stain gauges. Simultaneously, arterial oxygen saturation $\left(\mathrm{S}_{\mathrm{a}}, \mathrm{O}_{2}\right)$ was monitored with a pulse oximeter (Pulsox DP-8, Minolta, Osaka, Japan). Sleep was analysed using the standard criteria [19] for epochs of 20 s and the following sleep variables were calculated: total sleep time, wake time after sleep onset and sleep efficiency, defined as the ratio of total sleep time to sleep episode duration. Micro-arousals were scored according to the American Sleep Disorders Association (ASDA) definition [20]. An obstructive apnoea/hypopnoea event was characterised by a $>50 \%$ decrease from baseline in the amplitude of breathing for $\geqslant 10 \mathrm{~s}$ associated with either $\mathrm{O}_{2}$ desaturation of $>3 \%$ or an arousal in the presence of continued respiratory efforts [21]. The apnoea/hypopnoea index (AHI) was established as the number of apnoeas/hypopnoeas per hour of sleep. The number of arousals per hour of sleep was expressed as the arousal index (ARI). OSAHS was defined as excessive daytime sleepiness unexplained by other factors plus five or more obstructed breathing events per hour during sleep [21]. As indices of nocturnal $\mathrm{O}_{2}$ saturation, the mean $\mathrm{S}_{\mathrm{a}} \mathrm{O}_{2}$ throughout the night, the mean low $\mathrm{Sa}_{\mathrm{a}} \mathrm{O}_{2}$ (mean of the minimum value for $\mathrm{Sa}, \mathrm{O}_{2}$ in each 30-s epoch) and the minimum $S_{\mathrm{a}, \mathrm{O}_{2}}$ (lowest values recorded during sleep) were computed.

Respiratory function. Immediately after awakening, pulmonary function tests were performed as previously described [22], with subjects seated, and always in the same order allowing enough rest between each manoeuvre. All procedures were performed by the same technician, blinded to the results.

Arterial blood gas values were measured with subjects in a seated position, while they breathed room air. Spirometry was performed by means of a pneumotachograph and static lung volumes were measured with a constant-volume body plethysmograph (MasterLab Body, Erich Jaeger GmbH, Würzburg, Germany), according to European Respiratory Society standardisation [23]. Resting $\mathrm{O}_{2}$ uptake and carbon dioxide $\left(\mathrm{CO}_{2}\right)$ output were measured over 5 min, using an automated ergometry set up (Oxycon Alpha, Jaeger). Mean values of the last 4 mins were taken for analysis.

Maximal static inspiratory pressure $(P \mathrm{I}, \max )$ was measured using a differential pressure transducer (M-163; Sibelmed, Barcelona, Spain). Patients, comfortably seated and wearing a noseclip, performed maximal respiratory efforts either at residual volume or at total lung capacity against an obstructed mouthpiece with a small leak (internal diameter, $0.7 \mathrm{~mm}$ ) to minimise oral pressure artifacts. The manoeuvres were repeated until three measurements sustained for $\geqslant 3 \mathrm{~s}$ and with $<5 \%$ variability were recorded. The highest value obtained was used for analysis.

Mouth occlusion pressure at $0.1 \mathrm{~s}$ after the beginning of inspiration $\left(P_{0.1}\right)$ was measured by the Whitelaw method [24]. Mouth pressure was recorded with a differential pressure transducer (Model DWD, Jaeger). Approximately every $15 \mathrm{~s}$ the inspiratory line was occluded without the subject's knowledge for $<0.5 \mathrm{~s}$ by means of a pneumatic inflatable balloon (Series 9327; Hans-Rudolph, St. Louis, MO, USA). The mean of five or more measurements was determined. The values for dead space and resistance of the system up to a flow of $100 \mathrm{~mL}$ were $173 \mathrm{~mL}$ and $0.1 \mathrm{kPa} \cdot \mathrm{s} \cdot \mathrm{L}^{-1}$, respectively.

Ventilatory and $P 0.1$ responses to progressive isocapnic hypoxia were determined using the rebreathing method of ReBuck and CAmpbell [17]. $\mathrm{Sa}_{\mathrm{a}} \mathrm{O}_{2}$ was measured continuously with a finger-pulse oximeter (model Oscar II, Datex, Helsinki, Finland). In the seated position with noseclips applied, subjects breathed room air through a mouthpiece via a threeway valve while expired gas was continuously sampled at the mouthpiece using a rapidly responding infrared $\mathrm{CO}_{2}$ analyser (model Oscar II, Datex). The gas analyser was calibrated with gases previously analysed by the Scholander technique. After a stable end-tidal $\mathrm{CO}_{2}$ concentration was achieved, subjects rebreathed through a 7-1 bag containing the initial gas mixture: $21 \% \mathrm{O}_{2}$ and $7 \% \mathrm{CO}_{2}$ in nitrogen $\left(\mathrm{N}_{2}\right) . \mathrm{CO}_{2}$ was held constant (end-tidal $\mathrm{CO}_{2}$ tension $\left(P\right.$ et, $\left.\mathrm{CO}_{2}\right) \pm 1 \mathrm{mmHg}$ ) at the resting end-tidal level ("mixed-venous") using a variable $\mathrm{CO}_{2}$ absorber bypass, containing soda lime $\mathrm{CO}_{2}$ absorbent and a variable fan. Inspiratory minute 
ventilation $\left(V^{\prime} \mathrm{I}\right)$ was measured by electrically integrating the inspiratory flow signal obtained with a heated $\left(37^{\circ} \mathrm{C}\right)$ pneumotachograph (Screenmate Box, Jaeger). Approximately every 15 s without the subject's knowledge, $P 0.1$ was recorded as indicated previously. $V^{\prime} \mathrm{I}$, $P 0.1, \mathrm{Sa}_{2} \mathrm{O}_{2}$ and $P$ et, $\mathrm{CO}_{2}$ were displayed on a 12-bit analogue digital board and a personal computer running LabVIEW software (National Instruments, Austin, Texas, USA). Signals were sampled at $100 \mathrm{~Hz}$. $P 0.1$ was measured from each tracing. $V^{\prime} \mathrm{I}$ and $P_{0.1}$ were plotted against $S \mathrm{a}, \mathrm{O}_{2}$ on linear coordinates and the slopes were calculated by least-squares linear regression. The procedure was terminated when the $\mathrm{Sa}, \mathrm{O}_{2}$ reached $80 \%$.

Peripheral chemosensitivity was detected as a fall of

Table 1.-Anthropometric characteristics, lung function and sleep architectures in control subjects and patients with obstructive sleep apnoea-hypopnoea syndrome (OSAHS)

\begin{tabular}{|c|c|c|}
\hline & $\begin{array}{l}\text { Control } \\
\text { subjects }\end{array}$ & $\begin{array}{c}\text { Patients } \\
\text { with OSAHS }\end{array}$ \\
\hline Sex M:F & $10: 3$ & $14: 5$ \\
\hline Age yr & $56 \pm 13$ & $54 \pm 8$ \\
\hline Weight kg & $81 \pm 14$ & $88 \pm 14$ \\
\hline Height $\mathrm{m}$ & $1.62 \pm 0.11$ & $1.69 \pm 0.09$ \\
\hline $\mathrm{BMI} \mathrm{kg} \cdot \mathrm{m}^{-2}$ & $30.9+3.0$ & $30.8+3.6$ \\
\hline Smokers \% & $\overline{31}$ & $\overline{21}$ \\
\hline $\begin{array}{l}\text { Total sleep } \\
\text { time min }\end{array}$ & $373 \pm 42$ & $316 \pm 24$ \\
\hline Sleep efficiency $\%$ & $85 \pm 8$ & $71 \pm 6^{*}$ \\
\hline $\begin{array}{l}\text { Sleep onset } \\
\text { latency } \min \end{array}$ & $33 \pm 12$ & $10 \pm 8^{* *}$ \\
\hline WASO min & $32 \pm 36$ & $105 \pm 22 * *$ \\
\hline $\mathrm{AHI}^{-1}$ & $2.4 \pm 1.4$ & $47.3 \pm 22.9 * *$ \\
\hline ARI $h^{-1}$ & $2.0 \pm 1.3$ & $34.4 \pm 13.4 * *$ \\
\hline Mean $S_{\mathrm{a}, \mathrm{O}_{2}} \%$ & $96 \pm 1$ & $93 \pm 5$ \\
\hline $\begin{array}{l}\text { Mean low } \\
\qquad S_{\mathrm{a}, \mathrm{O}_{2}} \%\end{array}$ & $90 \pm 1$ & $79 \pm 9 * *$ \\
\hline $\begin{array}{r}\text { Minimum } \\
\mathrm{S}_{\mathrm{a}, \mathrm{O}_{2}} \%\end{array}$ & $89 \pm 2$ & $74 \pm 8^{* *}$ \\
\hline FVC L & $3.30 \pm 1.01$ & $3.78 \pm 0.79$ \\
\hline FEV1 L & $2.52 \pm 0.86$ & $3.08 \pm 0.74$ \\
\hline TLC L & $5.75 \pm 1.29$ & $6.32 \pm 1.03$ \\
\hline FRC L & $3.22 \pm 0.84$ & $2.94 \pm 0.61$ \\
\hline RV L & $2.40 \pm 1.05$ & $2.40 \pm 0.59$ \\
\hline$P \mathrm{I}, \max \mathrm{kPa}$ & $10.0 \pm 2.2$ & $11.1 \pm 3.1$ \\
\hline $\mathrm{pH}$ & $7.41 \pm 0.03$ & $7.40 \pm 0.03$ \\
\hline$P \mathrm{a}, \mathrm{O}_{2} \mathrm{mmHg}$ & $79.4 \pm 4.4$ & $73.9 \pm 9.1$ \\
\hline$P \mathrm{a}, \mathrm{CO}_{2} \mathrm{mmHg}$ & $37.5 \pm 3.1$ & $38.9 \pm 3.8$ \\
\hline$V^{\prime} \mathrm{O}_{2} \mathrm{~L} \cdot \min ^{-1}$ & $0.284 \pm 0.053$ & $0.303 \pm 0.080$ \\
\hline$V^{\prime} \mathrm{CO}_{2} \mathrm{~L} \cdot \mathrm{min}^{-1}$ & $0.242 \pm 0.052$ & $0.257 \pm 0.076$ \\
\hline$P 0.1 \mathrm{kPa}$ & $0.139 \pm 0.019$ & $0.205 \pm 0.045^{* *}$ \\
\hline
\end{tabular}

Data are presented as mean $\pm \mathrm{SD}$. M: male; F: female; BMI: body mass index; WASO: wake after sleep onset; AHI: apnoea-hypopnoea index; ARI: arousal index; $\mathrm{S}_{\mathrm{a}} \mathrm{O}_{2}$ : arterial oxygen saturation; FVC: forced vital capacity; FEV1: forced expiratory volume in one second; TLC: total lung capacity; FRC: functional residual capacity; RV: residual volume; $P$ I,max: maximal static inspiratory pressure; $\mathrm{Pa}_{\mathrm{a}} \mathrm{O}_{2}$ : oxygen tension in arterial blood; $P \mathrm{a}, \mathrm{CO}_{2}$ : carbon dioxide in arterial blood; $V^{\prime} \mathrm{O}_{2}$ : oxygen consumption; $V^{\prime} \mathrm{CO}_{2}$ : carbon dioxide output; P0.1: mouth occlusion pressure. ${ }^{*}: \mathrm{p}<0.05$ for the comparison with control group; $* *: \mathrm{p}<0.01$ for the comparison with control group. ventilation following sudden elimination of mild hypoxia $[7,25]$. At the beginning of the test, $V^{\prime} I$ and $P$ et, $\mathrm{CO}_{2}$ were measured while the subject was breathing room air from a rubber bag. $\mathrm{N}_{2}$ and $\mathrm{CO}_{2}$ were then added to obtain a end-tidal $\mathrm{O}_{2}$ tension $\left(P\right.$ et, $\left.\mathrm{O}_{2}\right)$ of $60 \mathrm{mmHg}$ and $P$ et, $\mathrm{CO}_{2} 5 \mathrm{mmHg}$ higher than the control. Two breaths of $\mathrm{O}_{2}$ were then given by turning a three-way stopcock near the inlet of the respiratory valve, to raise $P$ et, $\mathrm{O}_{2}>200 \mathrm{mmHg}$. $P$ et, $\mathrm{CO}_{2}$ was also decreased by $2-3 \mathrm{mmHg}$ because inspired $\mathrm{CO}_{2}$ pressure decreased to zero at this time [25]. After two breaths of $100 \% \mathrm{O}_{2}$, the inspiratory gas was switched back to the hypercapnic hypoxic gas. The $V^{\prime}$ I during room-air breathing was defined as $V^{\prime} \mathrm{I}, \mathrm{N}$. The $V^{\prime} \mathrm{I}$ before breathing $100 \% \mathrm{O}_{2}$ during the mildly hypercapnic hypoxic state was defined as $V^{\prime} \mathrm{I}, 0$. The $\mathrm{V}^{\prime} \mathrm{I}$ between 5 and $20 \mathrm{~s}$ after changing the inspiratory gas was defined as $V^{\prime}$ I,5-20. The difference between $V^{\prime}$ I, 0 and $V^{\prime} \mathrm{I}, 5-20$ was defined as the withdrawal response $\left(\Delta V^{\prime} \mathrm{I}\right)$ and $\% \Delta V^{\prime} \mathrm{I}\left(\Delta V^{\prime} \mathrm{I} / V^{\prime} \mathrm{I}, 0 \times 100\right)$ was used as an index of the peripheral chemoreceptor activity. The withdrawal test was performed three or more times at intervals of $20 \mathrm{~min}$. The subject breathed room air between tests to avoid the effects of hypoxic ventilatory depression [7]. To eliminate the effects of body size and sex, the indices of each ventilatory response were corrected by body surface area (BSA).

\section{Analysis}

The comparisons between the patients with OSAHS and the control subjects were performed by the MannWhitney U-test. Coefficient of variability was computed as $100 \times$ standard deviation (SD) of the repeated determinations divided by the mean value $(100 \times \mathrm{SD}$. mean $\left.^{-1}\right)$. Correlations between respiratory responses to progressive isocapnic hypoxic stimulation and the

Table 2.-Respiratory responses to chemical stimuli in control subjects and patients with obstructive sleep apnoea-hypopnoea syndrome (OSAHS)

\begin{tabular}{ccc}
\hline & $\begin{array}{c}\text { Control } \\
\text { subjects }\end{array}$ & $\begin{array}{c}\text { Patients } \\
\text { with OSAHS }\end{array}$ \\
\hline$\Delta V^{\prime} \mathrm{I} / \mathrm{Sa}_{\mathrm{a}, \mathrm{O}_{2} / \mathrm{BSA}}$ & $0.455 \pm 0.006$ & $0.261 \pm 0.003^{* *}$ \\
$\mathrm{~L} / \mathrm{min} / \% / \mathrm{m}^{2}$ & $0.0033 \pm 0.0003$ & $0.0024 \pm 0.0004^{* *}$ \\
$\Delta P_{0.1} / \mathrm{S}_{\mathrm{a}}, \mathrm{O}_{2}$ & $5.45 \pm 0.36$ & $5.43 \pm 0.46$ \\
$\mathrm{kPa} / \%$ & $10.9 \pm 1.78$ & $6.55 \pm 0.78^{* *}$ \\
$\Delta V^{\prime} \mathrm{I}, \mathrm{N} / \mathrm{BSA}$ & $3.60 \pm 0.50$ & $1.57 \pm 0.30^{* *}$ \\
$\mathrm{~L} / \mathrm{min} / \mathrm{m}^{2}$ & $33.0 \pm 2.8$ & $24.0 \pm 3.6^{* *}$ \\
$\Delta V^{\prime} \mathrm{I}, 0 / \mathrm{BSA}$ & $\mathrm{L} / \mathrm{min} / \mathrm{m}^{2}$ & \\
$\Delta V^{\prime} \mathrm{I} / \mathrm{BSA}$ \\
$\mathrm{L} / \mathrm{min} / \mathrm{m}^{2}$ & &
\end{tabular}

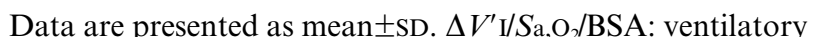
response to progressive isocapnic hypoxic stimulation; $\Delta P 0.1 / \mathrm{S}_{\mathrm{a}, \mathrm{O}_{2}}$ : central inspiratory drive response to progressive isocapnic hypoxic stimulation; $\Delta V^{\prime} \mathrm{I}, \mathrm{N} / \mathrm{SA}$ : inspiratory minute ventilation during room air breathing; $\Delta V^{\prime} \mathrm{I}, 0 / \mathrm{BSA}$ : inspiratory minute ventilation during mildly hypercapnic hypoxic state; $\Delta V^{\prime}$ I: withdrawal response. ${ }^{* *}: \mathrm{p}<0.01$ for the comparison with control group. 
hypoxic withdrawal test were analysed by linear regression analysis, using Spearman's rank correlation coefficient (r). In order to determine which independent variables were correlated with hypoxic withdrawal response, stepwise multiple linear regression analysis was performed [26]. Independent variables entered into the regression included AHI, ARI, mean lowest $\mathrm{Sa}, \mathrm{O}_{2}$, minimum $\mathrm{Sa}, \mathrm{O}_{2}, \mathrm{O}_{2}$ uptake and $\mathrm{CO}_{2}$ production. Stepwise criteria were a probability of F-Snedecor test to enter $<0.05$ and a probability of $\mathrm{F}$-Snedecor test to remove $>0.10$. In all cases, $p$-values of $<0.05$ were considered to be significant. Data are expressed as mean \pm SD.

\section{Results}

The anthropometric characteristics of the patients with OSAHS and the control subjects are shown in table 1 . There was no significant difference in sex, age,
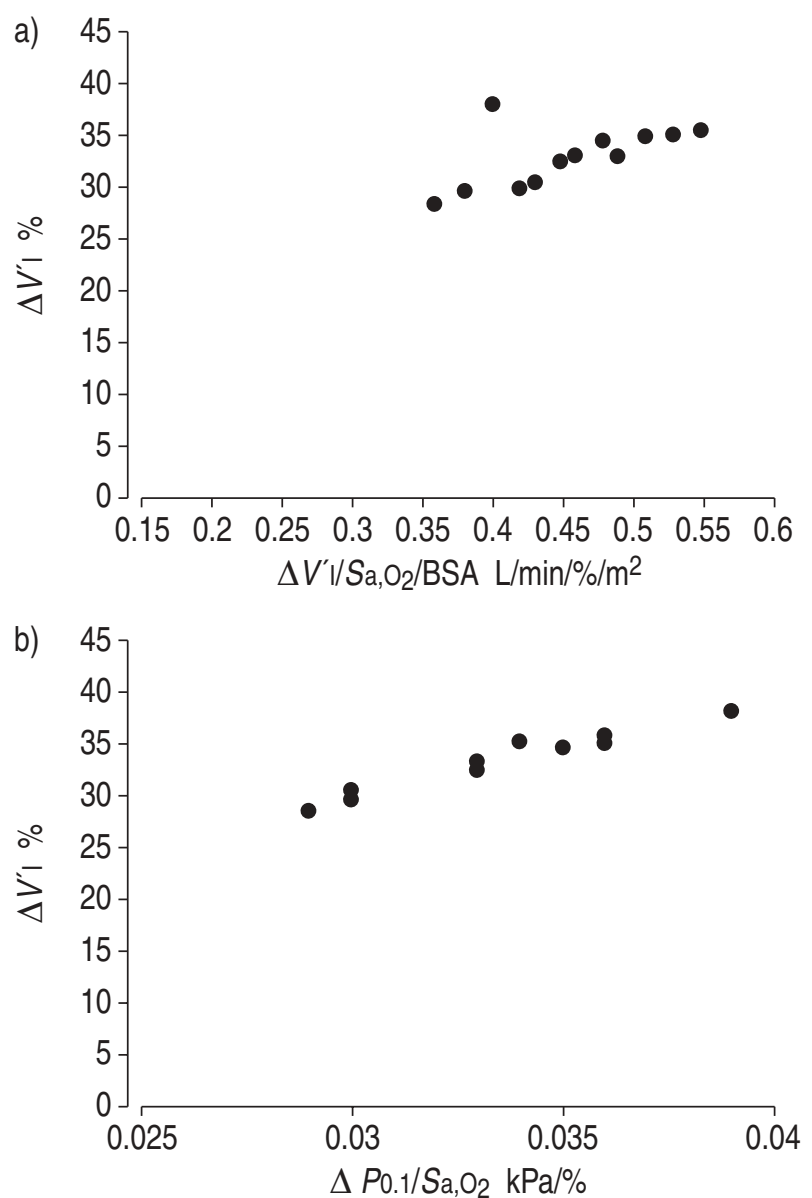

Fig. 1.-a) Ventilatory and b) inspiratory neural drive responses to progressive isocapnic hypoxic stimulation plotted against hypoxic withdrawal in control subjects. $\Delta V^{\prime} \mathrm{I}$ : withdrawal response; $\% \Delta V^{\prime} \mathrm{I}: \Delta V^{\prime} \mathrm{I} / V^{\prime} \mathrm{I}, 0 \times 100$, where $V^{\prime} \mathrm{I}, 0$ is $V^{\prime} \mathrm{I}$ before breathing $100 \% \mathrm{O}_{2}$ during the mildly hypercapnic hypoxic state. $S_{\mathrm{a}, \mathrm{O}_{2}}$ : arterial oxygen saturation; BSA: body surface area; $\Delta V^{\prime} \mathrm{I} / \mathrm{S}_{\mathrm{a}, \mathrm{O}_{2}} /$ BSA: ventilatory response to progressive isocapnic hypoxic stimulation; $P_{0.1}$ : mouth occlusion pressure; $\Delta P_{0.1} / \mathrm{Sa}_{\mathrm{a}} \mathrm{O}_{2}$ : central inspiratory drive response to progressive isocapnic hypoxic stimulation. (a) $\mathrm{r}=0.685, \mathrm{p}=0.010$; b) $\mathrm{r}=0.961, \mathrm{p}=0.000$ ). body mass index or smoking habit between both groups.

The mean values of lung volumes, PI,max, arterial blood gases, $\mathrm{O}_{2}$ uptake and $\mathrm{CO}_{2}$ production were similar in both groups. Of the basal lung function tests, only $P_{0.1}$ was significantly higher $(\mathrm{p}<0.001)$ in the OSAHS patients than in the control subjects.

The respiratory responses to hypoxia are shown in table 2. Compared with control subjects, patients with OSAHS had lower ventilatory and inspiratory neural drive responses to progressive isocapnic hypoxic stimulation $(\mathrm{p}<0.001)$. There was no significant difference in $V^{\prime}$ I during room air breathing. The mean values of $V^{\prime}$ I during mildly hypercapnic hypoxic state $\left(\Delta V^{\prime} \mathrm{I}, 0 / \mathrm{BSA}\right)$ and withdrawal response $\left(\Delta V^{\prime} \mathrm{I} /\right.$ BSA and $\left.\% \Delta V^{\prime} \mathrm{I}\right)$ for patients with OSAHS were lower than those for the control subjects.

In control subjects, withdrawal response was correlated with ventilatory and $P_{0.1}$ responses to progressive isocapnic hypoxic stimulation (fig. 1). As
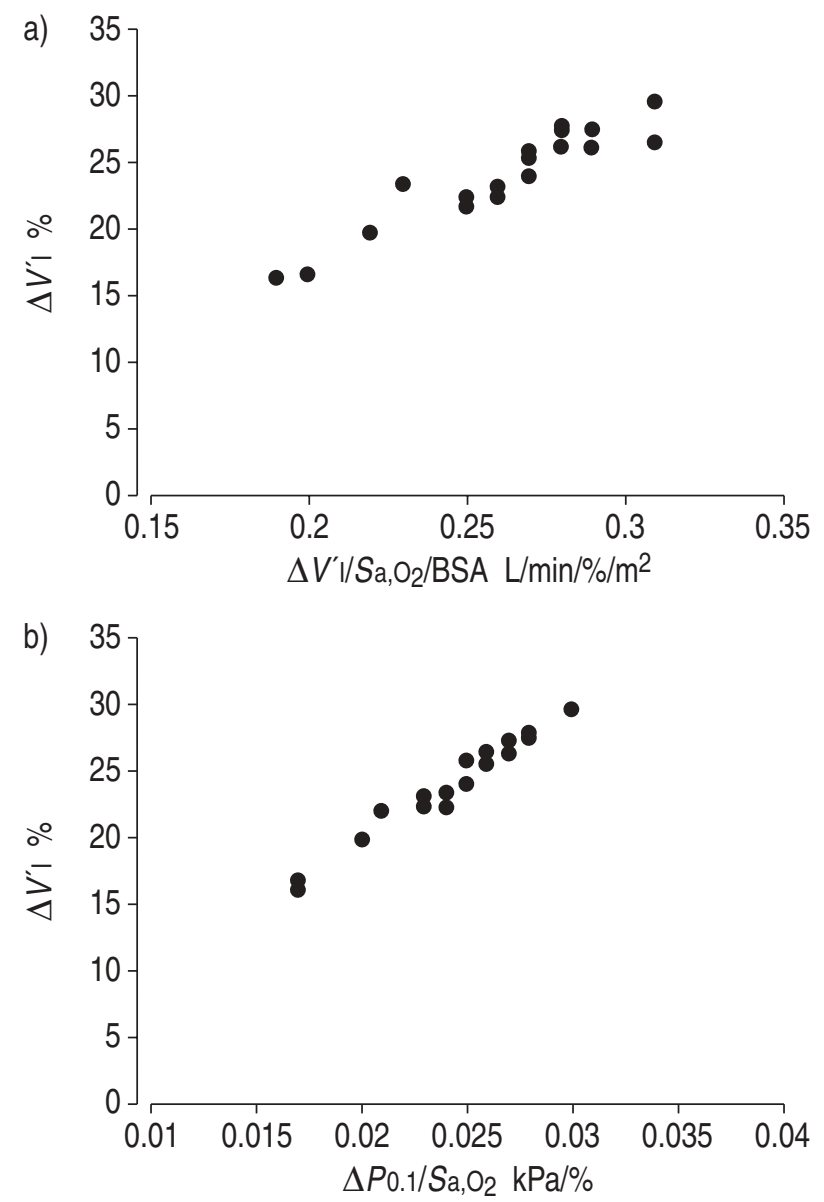

Fig. 2.-a) Ventilatory and b) inspiratory neural drive responses to progressive isocapnic hypoxic stimulation plotted against hypoxic withdrawal in patients with obstructive sleep apnoeahypopnoea syndrome (OSAHS). $\Delta V^{\prime} \mathrm{I}$ : withdrawal response;

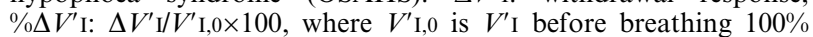
$\mathrm{O}_{2}$ during the mildly hypercapnic hypoxic state. $\mathrm{Sa}_{\mathrm{a}} \mathrm{O}_{2}$ : arterial oxygen saturation; BSA: body surface area; $\Delta V^{\prime} \mathrm{I} / \mathrm{S}_{\mathrm{a}, \mathrm{O}_{2}} / \mathrm{BSA}$ : ventilatory response to progressive isocapnic hypoxic stimulation; $P_{0.1}$ : mouth occlusion pressure; $\Delta P_{0.1} / S_{\mathrm{a}, \mathrm{O}_{2}}$ : central inspiratory drive response to progressive isocapnic hypoxic stimulation. a) $\mathrm{r}=0.976, \mathrm{p}=0.000$; b) $\mathrm{r}=0.926$; $\mathrm{p}=0.000$. 

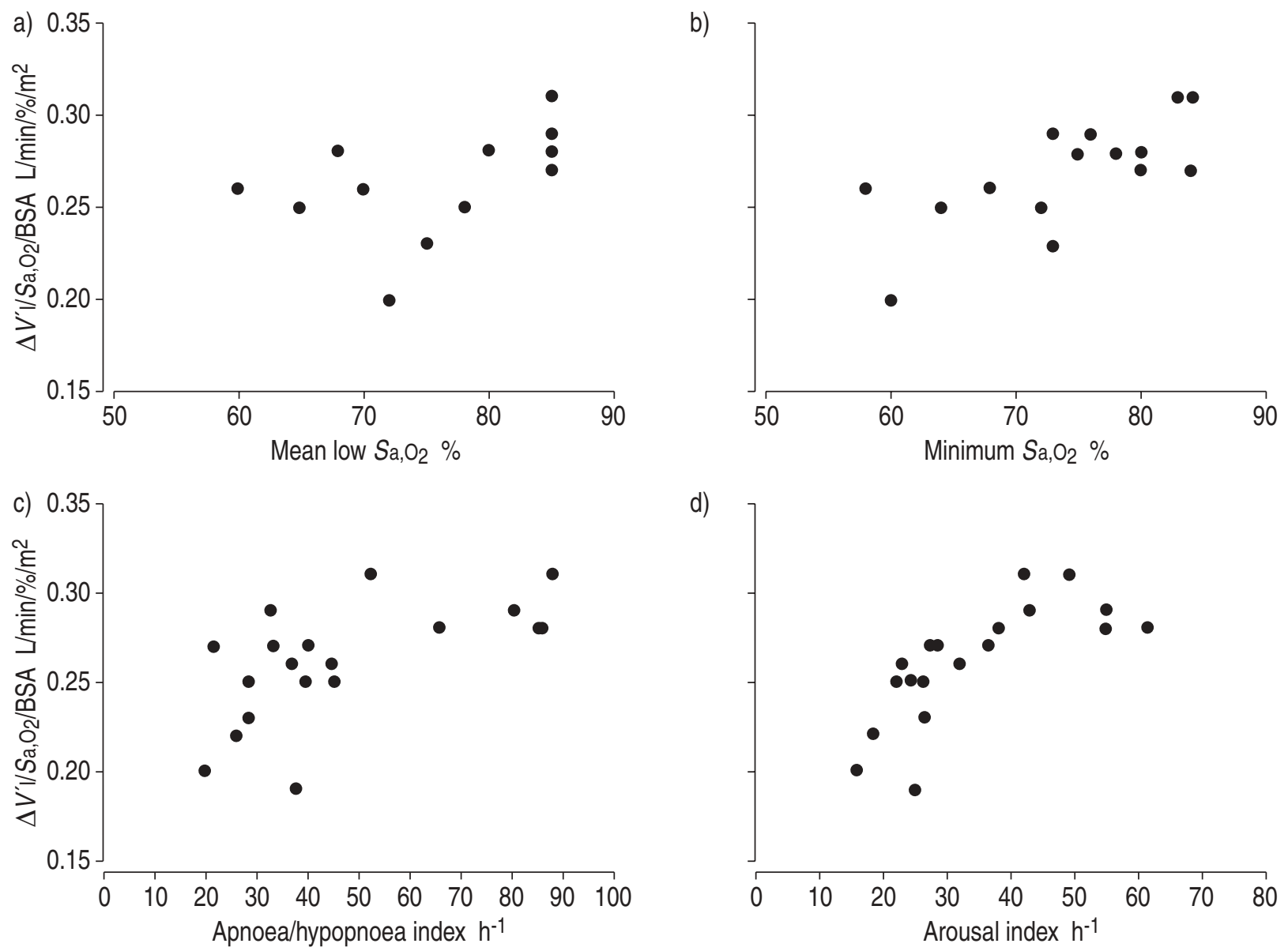

Fig. 3. - Relationship between a) mean nocturnal arterial oxygen saturation $\left(S_{\mathrm{a}, \mathrm{O}_{2}}\right)$, b) minimum $S_{\mathrm{a}, \mathrm{O}_{2}}$, c) apnoea/hypopnoea index and d)

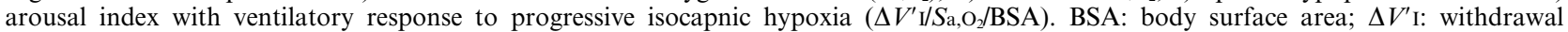
response. a) $\mathrm{r}=0.732, \mathrm{p}=0.002$; b) $\mathrm{r}=0.697, \mathrm{p}=0.004 \mathrm{c}$ ) $\mathrm{r}=0.649, \mathrm{p}=0.003$; d) $\mathrm{r}=0.864 ; \mathrm{p}=0.000$.

shown in figure 2, patients with OSAHS had significant correlations between $\Delta V^{\prime} \mathrm{I} / \mathrm{S}_{\mathrm{a}}, \mathrm{O}_{2} / \mathrm{BSA}$ and $\% \Delta V^{\prime} \mathrm{I}$, and between $\Delta P 0.1 / \mathrm{Sa}_{\mathrm{a}} \mathrm{O}_{2}$ and $\% \Delta V^{\prime} \mathrm{I}$. On stepwise multiple linear regression analysis, \% $\Delta V^{\prime} \mathrm{I}$ significantly correlated with $\Delta P 0.1 / S \mathrm{a}, \mathrm{O}_{2}$ (multiple $\mathrm{r}^{2}=0.970$, $\mathrm{p}=0.000)$ in patients with OSAHS.

Within-day coefficients of variation for chemosensitivity indices as assessed in all OSAHS patients for three study sessions were $6.1 \%$ (range, $2.0-8.5 \%$ ) for $\Delta V^{\prime} \mathrm{I} / S_{\mathrm{a}}, \mathrm{O}_{2} / \mathrm{BSA}, 5.8 \%$ (range, $1.7-8.0 \%$ ) for $\Delta P_{0.1} /$ $S \mathrm{a}, \mathrm{O}_{2}$, and $8.3 \%$ (range, $3.2-12.4 \%$ ) for $\% \Delta V^{\prime}$ I. Dayto-day coefficients of variation as assessed in eight patients with OSAHS on three different days, were 9.1\% (range, $3.3-13.5 \%$ ) for $\Delta V^{\prime} \mathrm{I} / \mathrm{S}_{\mathrm{a}}, \mathrm{O}_{2} / \mathrm{BSA}, 8.9 \%$ (range, $4.1-12.6 \%$ ) for $\Delta P 0.1 / \mathrm{Sa}_{\mathrm{O}} \mathrm{O}_{2}$, and $12.6 \%$ (range, $5.2-18.1 \%$ ) for $\% \Delta V^{\prime}$ I.

In OSAHS patients, $\Delta V^{\prime} \mathrm{I} / \mathrm{Sa}_{\mathrm{a}} \mathrm{O}_{2} / \mathrm{BSA}$ correlated with mean low $\mathrm{Sa}_{\mathrm{a}} \mathrm{O}_{2}(\mathrm{r}=0.732, \mathrm{p}=0.002)$, minimum $\mathrm{Sa}_{\mathrm{O}} \mathrm{O}_{2}$ $(\mathrm{r}=0.697, \mathrm{p}=0.004)$, AHI $(\mathrm{r}=0.649, \mathrm{p}=0.003)$ and ARI $(\mathrm{r}=0.864, \mathrm{p}=0.000)$ (fig. 3$) . \Delta P 0.1 / S_{\mathrm{a}}, \mathrm{O}_{2}$ also correlated with mean low $S \mathrm{a}, \mathrm{O}_{2}(\mathrm{r}=0.824, \mathrm{p}=0.000)$, minimum $S \mathrm{a}, \mathrm{O}_{2}(\mathrm{r}=0.771, \mathrm{p}=0.001)$, AHI $(\mathrm{r}=0.650, \mathrm{p}=0.003)$ and ARI ( $\mathrm{r}=0.902, \mathrm{p}=0.000$ ) (fig. 4). Indeed, $\% \Delta V^{\prime}$ I correlated with mean low $\mathrm{Sa}_{\mathrm{a}} \mathrm{O}_{2}(\mathrm{r}=0.816, \mathrm{p}=0.000)$, minimum $S \mathrm{a}, \mathrm{O}_{2}(\mathrm{r}=0.768, \mathrm{p}=0.001)$, AHI (r=0.676, $\left.\mathrm{p}=0.001\right)$ and ARI ( $\mathrm{r}=0.913, \mathrm{p}=0.000)$ (fig. 5). $\mathrm{O}_{2}$ uptake and $\mathrm{CO}_{2}$ production were related with $\Delta P 0.1 / \mathrm{Sa}_{\mathrm{a}} \mathrm{O}_{2}(\mathrm{r}=$ $0.582, \mathrm{p}=0.009$ and $\mathrm{r}=0.576, \mathrm{p}=0.010$, respectively) and with $\% \Delta V^{\prime} \mathrm{I}(\mathrm{r}=0.553, \mathrm{p}=0.014$ and $\mathrm{r}=0.560, \mathrm{p}=0.013$, respectively), but they did not correlate with $\Delta V^{\prime}$ I/ $\mathrm{Sa}_{\mathrm{a}} \mathrm{O}_{2} / \mathrm{BSA} \quad \mathrm{r}=0.375, \mathrm{p}=0.114$ and $\mathrm{r}=0.386, \mathrm{p}=0.103$, respectively). No correlations were found between the withdrawal response and mean nocturnal $\mathrm{Sa}_{\mathrm{a}} \mathrm{O}_{2}$ $(\mathrm{r}=-0.238, \mathrm{p}=0.455), \mathrm{pH} \quad(\mathrm{r}=-0.234, \mathrm{p}=0.336), \quad \mathrm{CO}_{2}$ tension in arterial blood $\left(P \mathrm{a}, \mathrm{CO}_{2}\right)(\mathrm{r}=0.086, \mathrm{p}=0.726)$, functional residual capacity $(\mathrm{r}=0.290, \mathrm{p}=0.242), P \mathrm{I}$,max $(\mathrm{r}=0.175, \mathrm{p}=0.473)$ or central inspiratory drive $(\mathrm{r}=-0.192, \mathrm{p}=0.430)$. On stepwise multiple linear regression for $\% \Delta V^{\prime} \mathrm{I}$ as dependent variable, the variables entered into the more significant model $\left(\mathrm{r}=0.882\right.$, adjusted $\left.\mathrm{r}^{2}=0.740\right)$ were ARI (standardised coefficient beta $=0.551, \mathrm{p}=0.009$ ) and minimum $\mathrm{Sa}_{\mathrm{a}} \mathrm{O}_{2}$ (standardized coefficient beta $=0.422, \mathrm{p}=0.034$ ).

\section{Discussion}

The main results of the present study are the following: peripheral chemosensitivity is reduced in OSAHS patients in comparison with control subjects; 

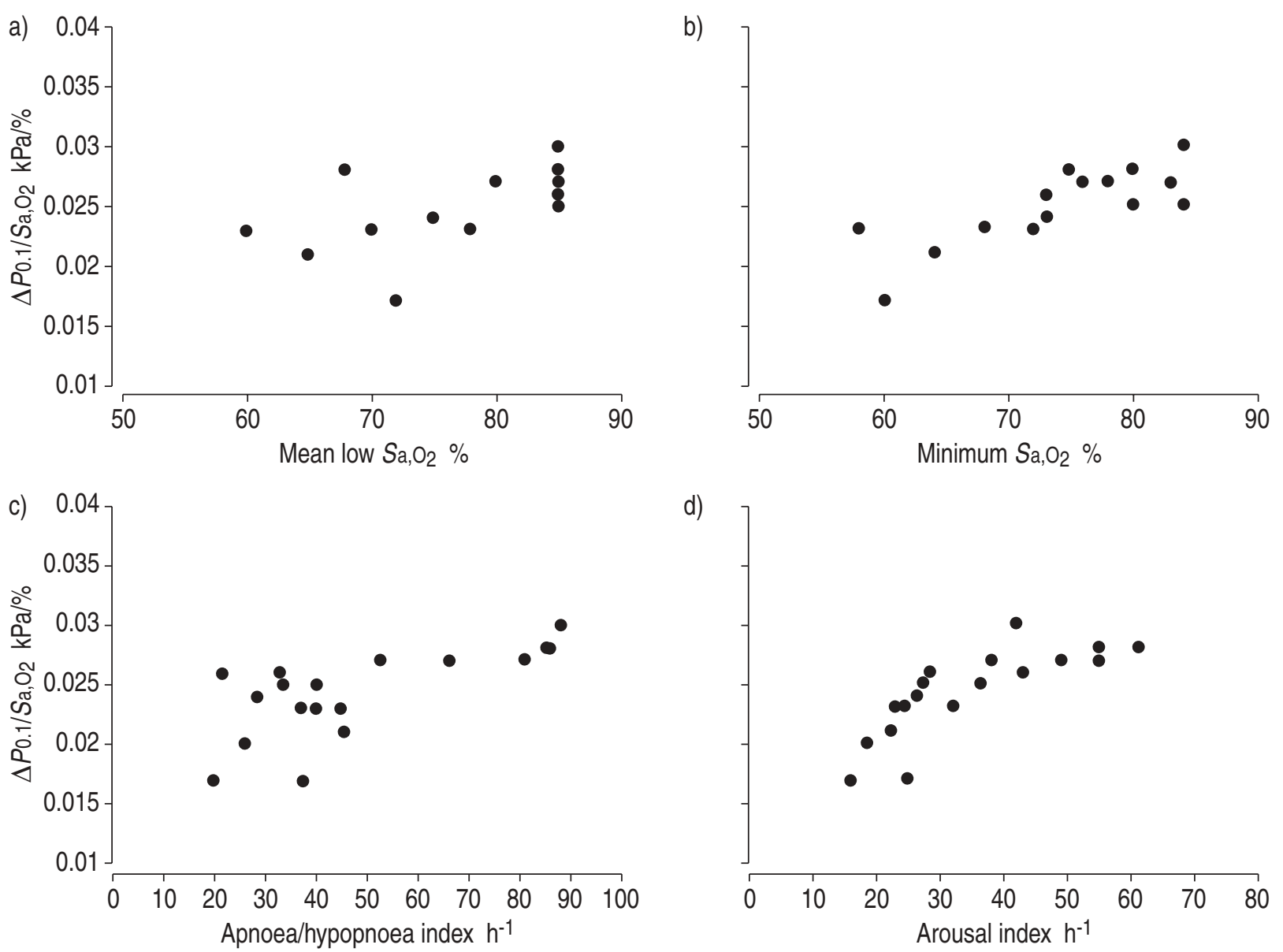

Fig. 4. - Relationship between a) mean nocturnal arterial oxygen saturation $\left(S_{\mathrm{a}, \mathrm{O}_{2}}\right)$, b) minimum $\left.S_{\mathrm{a}, \mathrm{O}_{2}}, \mathrm{c}\right)$ apnoea/hypopnoea index and d) arousal index with inspiratory neural drive response to progressive isocapnic hypoxia $\left(\Delta P_{0.1} / S_{a}, O_{2}\right)$. $P_{0.1}$ : mouth occlusion pressure. (a) $\mathrm{r}=0.824$, $\mathrm{p}=0.000$; b) $\mathrm{r}=0.771, \mathrm{p}=0.001$; $\mathrm{c}) \mathrm{r}=0.650, \mathrm{p}=0.003$; d) $\mathrm{r}=0.902, \mathrm{p}=0.000$ ).

the sensitivity of carotid body is strongly related with inspiratory neural drive response to progressive isocapnic hypoxic stimulation; and peripheral chemosensitivity of OSAHS patients is related to sleep disruption and to nocturnal hypoxaemia.

There are several factors to be considered when interpreting the decreased peripheral chemosensitivity of the patient group. Differences in age, body size and lung volumes could modify responses to chemical stimuli [27]. However, none of these varied between the OSAHS and control subjects. It is also known that chemosensitivity is highly dependent on the acid-base status of the patient. The respiratory response to hypoxia is sensitive to variations in arterial $\mathrm{pH}$ induced by partial pressure of $\mathrm{CO}_{2}$ changes. Specifically, acidosis and hypercapnia increase the response to hypoxia [27]. Only one of 19 OSAHS patients had a $\mathrm{Pa}_{2} \mathrm{CO}_{2}$ $>45 \mathrm{mmHg} \quad(46.8 \mathrm{mmHg}) . \Delta V^{\prime} \mathrm{I} / \mathrm{Sa}_{2} \mathrm{O}_{2} / \mathrm{BSA}, \quad \Delta P 0.1 /$ $\mathrm{Sa}_{\mathrm{a}, \mathrm{O}_{2}}$ and $\Delta V^{\prime} \mathrm{I}$ of this subject $\left(0.27 \mathrm{~L} / \mathrm{min} / \% / \mathrm{m}^{2}\right.$, $0.0250 \mathrm{kPa} / \%$ and $24.2 \%$, respectively) were higher than mean values of the OSAHS group (table 2). A hypercapnia-related increase in peripheral chemosensitivity could not be excluded in this patient. Thus, it is possible that the results slightly underestimate the true depression of peripheral chemosensitivity of OSAHS patients. The contribution of metabolic rate to the decrease in peripheral chemosensitivity should also be evaluated. The present results, which show similar levels of $\mathrm{O}_{2}$ consumption and $\mathrm{CO}_{2}$ production between OSAHS patients and control subjects, suggest that changes in the sensitivity of the carotid body of these patients are not due to lower basal metabolism.

A strong relationship between peripheral chemosensitivity and respiratory responses to progressive isocapnic hypoxic stimulation in OSAHS patients was found. These findings suggest that hypoxic stimulation of central chemoreceptors is minimally relevant in OSAHS patients. Thus, inspiratory neural drive response to hypoxia could be used to estimate peripheral chemosensitivity in these patients. Furthermore, a limitation of the withdrawal test should be considered. In the withdrawal test, the level of the stimulus varies with the tidal volume and frequency of the hyperoxic breaths, the initial alveolar $\mathrm{O}_{2}$ pressure, and the distribution of ventilation in the lungs [8]. Clearly, it would be difficult to apply this test in OSAHS patients in whom maldistribution of ventilation would prevent the relatively abrupt institution of a hyperoxic state, such as would occur in normal subjects.

This limitation of the withdrawal test in OSAHS patients could explain the slightly higher coefficients 

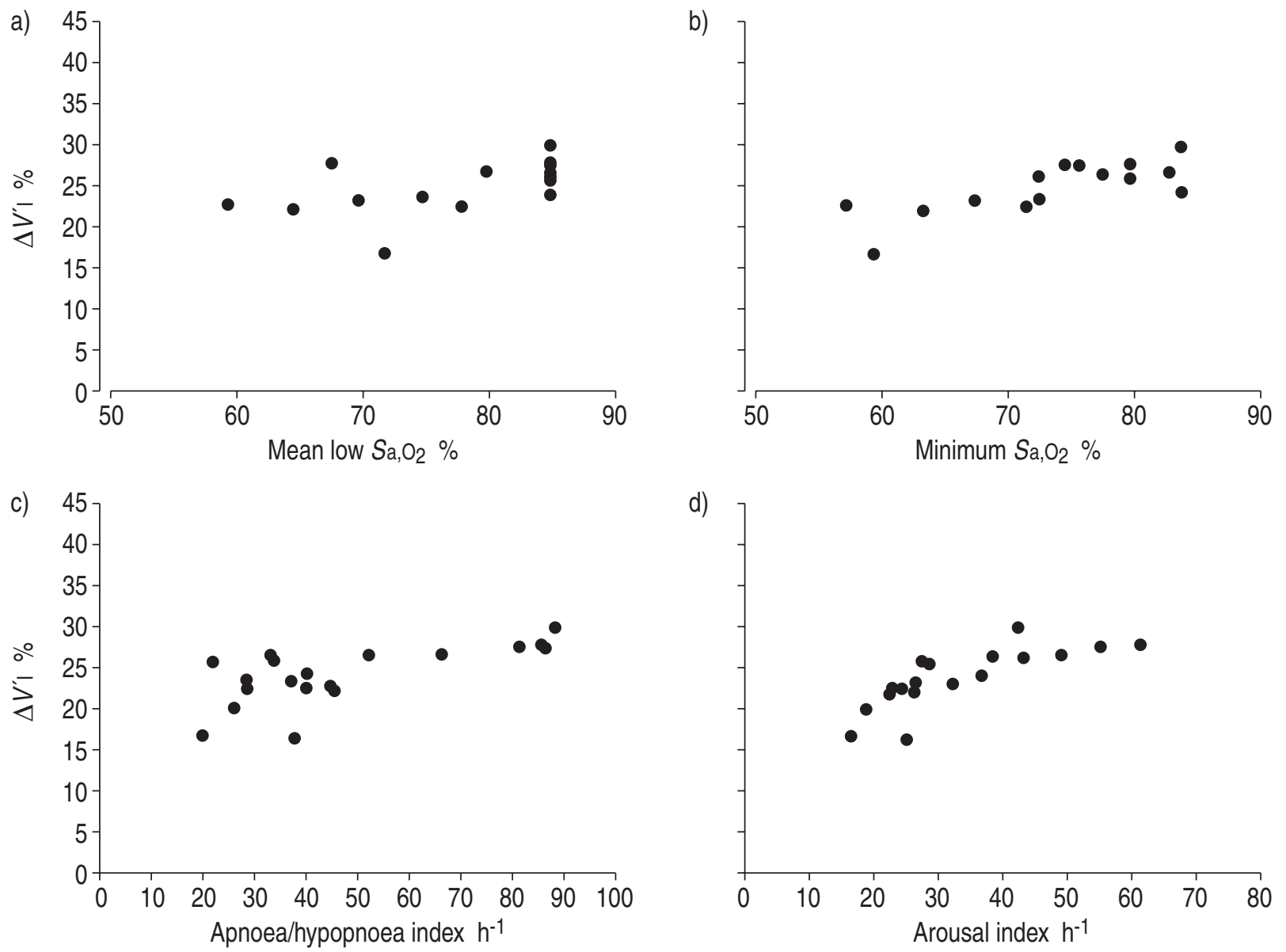

Fig. 5. - Relationship between a) mean nocturnal arterial oxygen saturation $\left(S_{\mathrm{a}}, \mathrm{O}_{2}\right)$, b) minimum $S_{\mathrm{a}, \mathrm{O}_{2}}$, c) apnoea/hypopnoea index and d) arousal index with hypoxic withdrawal response $\left(\Delta V^{\prime}\right.$ I). (a) $\left.\left.\left.\mathrm{r}=0.816, \mathrm{p}=0.000 ; \mathrm{b}\right) \mathrm{r}=0.768 ; \mathrm{p}=0.001 ; \mathrm{c}\right) \mathrm{r}=0.676 ; \mathrm{p}=0.001 ; \mathrm{d}\right) \mathrm{r}=0.913$, $\mathrm{p}=0.000)$.

of variation for $\% \Delta V^{\prime}$ I than for $P_{0.1}$ or ventilatory response to hypoxia found in this study. However, variability of both tests is moderate. Within-subject variability of hypoxic withdrawal response in the OSAHS patients $(12.6 \%)$ was equal to spontaneous variation estimated by OsANAI et al. [7] in healthy subjects. The coefficient of variability for $P 0.1$ response to hypoxia found in the OSAHS patients $(8.9 \%)$ was also similar to the coefficients of variability described by WHITE et al. [28] and the present authors' [29] in healthy subjects.

The mechanism of the reduced peripheral chemosensitivity in OSAHS patients is not well established. It seems probable that the diminished sensitivity of the carotid body represents a specific adaptation to the repeated hypoxia induced during apnoeas [30]. It is known that a reduction in ventilatory response to hypoxia occurs during both short- and long-term hypoxic exposure [31]. Although only very limited data exist on ventilatory changes during repeated hypoxia [30], the reduced peripheral chemosensitivity of OSAHS patients could represent an adaptive response to the hypoxic environment. Previous studies have shown that adaptation to sustained hypoxia may result from changes in either carotid chemoreceptors or central hypoxic sensitivity. The latter may be due either to altered central processing of afferent carotid body stimuli or to a change in direct central nervous system sensitivity to hypoxia [31]. The results of the present study do not exclude alterations in central processing of afferent stimuli, but show that central hypoxic stimulation is scarcely relevant.

In accordance with the role of hypoxia as an inducer of peripheral chemosensitivity alterations, a significant relationship between sensitivity of the carotid body and minimum nocturnal $\mathrm{O}_{2}$ saturation was found. Previously, it has been demonstrated that ventilatory responses to hypoxia are negatively correlated with the degree of hypoxaemia during sleep in OSAHS patients [32]. OsANAI et al. [7] reported that the hypoxic withdrawal response showed negative correlations with $4 \%$ - and $10 \%$-desaturation ratios. Contrary to these authors [7], the present authors found that peripheral chemosensitivity is also positively correlated with AHI. The importance of sleep structure as a contributing factor to peripheral chemosensitivity changes in OSAHS patients is not well known. Despite a reduction of ventilatory response to hypoxia after sleep deprivation having been demonstrated in healthy males [28], no relationship between diurnal sleepiness and chemosensitivity has been established. Previously, the present authors 
have proposed that repetitive abrupt arousals from sleep could be important contributors to the increase of the peripheral chemosensitivity in OSAHS patients [9]. The relationship between ARI and hypoxic withdrawal response found in the OSAHS patients in the present study might suggest a contribution of sleep disruption to changes in peripheral chemosensitivity. In consequence, it could be hypothesised that the sensitivity of the carotid body in OSAHS patients might be determined by a balance between hypoxic depression and arousal stimulation.

The sequence of events leading to a decrease in peripheral chemosensitivity in OSAHS patients is unresolved, but it has been proposed that these subjects have an abnormality of dopaminergic mechanisms in the peripheral chemoreceptors [7]. Since dopamine appears to be an inhibitory transmitter in mammalian carotid bodies, the effects of dopamine on the carotid body of patients with OSAHS might be increased [7]. On the other hand, familial aggregation of blunt ventilatory responses to chemical stimuli has been reported for healthy family members of OSAHS patients [33]. Thus a contribution of genetic factors to the changes in peripheral chemosensitivity observed in patients with OSAHS cannot be excluded.

To conclude, this study shows a strong relationship between peripheral chemosensitivity and the respiratory response to hypoxia in obstructive sleep apnoeahypopnoea syndrome patients, suggesting that hypoxic stimulation of central chemoreceptors is minimally relevant in these patients. Moreover the sensitivity of the carotid body in patients with obstructive sleep apnoea-hypopnoea syndrome is related to the apnoeahypopnoea index and with nocturnal oxygenation.

\footnotetext{
Acknowledgements. The investigators acknowledge the excellent technical assistance provided by A. Alvarez, P. Librán, A. Pérez and C. Suárez.
}

\section{References}

1. Narkiewicz K, van de Borne PJ, Pesek CA, Dyken ME, Montano N, Somers VK. Selective potentiation of peripheral chemoreflex sensitivity in obstructive sleep apnea. Circulation 1999; 99: 1183-1189.

2. Wilcox I, McNamara SG, Dodd MJ, Sullivan CE. Ventilatory control in patients with sleep apnoea and left ventricular dysfunction: comparison of obstructive and central sleep apnoea. Eur Respir J 1998; 11: 7-13.

3. Costes F, Court-Fortune I, Fournel P, Vergnon JM, Emonot A, Geyssant A. Study of chemosensitivity in patients believed to have sleep apnea syndrome. Rev Mal Respir 1995; 12: 359-364.

4. Wilcox I, Collins FL, Grunstein RR, Hedner J, Kelly DT, Sullivan CE. Relationship between chemosensitivity, obesity and blood pressure in obstructive sleep apnea. Blood Press 1994; 3: 47-54.

5. Gold AR, Schwartz AR, Wise RA, Smith PL. Pulmonary function and respiratory chemosensitivity in moderately obese patients with sleep apnea. Chest 1993; 103: 1325-1329.

6. Javaheri S, Colangelo G, Corser B, Zahedpour MR.
Familial respiratory chemosensitivity does not predict hypercapnia of patients with sleep apnea-hypopnea syndrome. Am Rev Respir Dis 1992; 145: 837840 .

7. Osanai S, Akiba Y, Fujiuchi S, et al. Depression of peripheral chemosensitivity by a dopaminergic mechanism in patients with obstructive sleep apnea syndrome. Eur Respir J 1999; 13: 418-423.

8. Burki NK. Measurements of ventilatory regulation. Clin Chest Med 1989; 10: 215-226.

9. García-Río F, Racionero MA, Pino JM, Martínez I, Ortuño F, Villasante C. Sleep apnea and hypertension. Chest 2000; 117: 1417-1425.

10. Tafil-Klawe M, Thiele AE, Raschke F, Mayer J, Peter $\mathrm{JH}$, von Wichert W. Peripheral chemoreceptor reflex in obstructive sleep apnea patients; a relationship between ventilatory response to hypoxia and nocturnal bradycardia during apnea events. Pneumologie 1991; 45: Suppl. 1, 309-311.

11. Sato F, Nishimura M, Shinano H, Saito H, Miyamoto K, Kamakami Y. Heart rate during obstructive sleep apnea depends on individual hypoxic chemosensitivity of the carotid body. Circulation 1997; 96: 274-281.

12. van de Borne P, Mark AL, Montano N, Mion D, Somers VK. Effects of alcohol on sympathetic activity, hemodynamics, and chemoreflex sensitivity. Hypertension 1997; 29: 1278-1283.

13. Kawakami Y, Yamamoto H, Yoshikawa T, Shida A. Respiratory chemosensitivity in smokers. Studies on monozygotic twins. Am Rev Respir Dis 1982; 126: 986990.

14. Kawakami Y, Yoshikawa T, Shide A. Chemical and behavioural control of breathing in adult twins. $J$ Appl Physiol 1982; 52: 537-543.

15. White DP, Douglas NJ, Pickett CK, Weil JV, Zwillich $\mathrm{CW}$. Sexual influence on the control of breathing. J Appl Physiol 1983; 54: 874-879.

16. Stockley RA, Lee KD. Estimation of the resting reflex hypoxic drive to respiration in patients with diffuse pulmonary infiltration. Clin Sci Mol Med 1976; 50: 109-114.

17. Rebuck AS, Campbell EJM. A clinical method for assessing the ventilatory response to hypoxia. Am Rev Respir Dis 1974; 109: 345-350.

18. Miller JP, Cunningham DJC, Lloyd BB, Young JM. The transient respiratory effects in man of sudden changes in alveolar $\mathrm{CO}_{2}$ in hypoxia and in high oxygen. Respir Physiol 1974; 20: 17-31.

19. Rechtschaffen A, Kales A. A manual of standardized terminology, techniques and scoring system for sleep stages of human subjects. Bethesda, National Institutes of Neurological Disease and Blindness, NIH publication No. 204, 1968.

20. American Sleep Disorders Association Atlas Task Force. EEG arousals: scoring rules and examples. Sleep 1992; 15: 173-186.

21. American Academy of Sleep Medicine Task Force. Sleep-related breathing disorders in adults: Recommendations for syndrome definition and measurement techniques in clinical research. Sleep 1999; 22: 667689.

22. Pino-García JM, García-Río F, Díez JJ, et al. Regulation of breathing in hyperthyroidism: relationship to hormonal and metabolic changes. Eur Respir $J$ 1998; 12: 400-407.

23. Quanjer PhH, Tammeling GJ, Cotes JE, Pederson OF, Peslin R, Yernault JC. Lung volumes and forced 
ventilatory flows. Report working party standardization of lung function tests. European Community for Steel and Coal. Official statement of the European Respiratory Society. Eur Respir J 1993; 6: Suppl., 16, 5-40.

24. Whitelaw W, Derenne JPh, Milic-Emili J. Occlusion pressure as a measure of respiratory center output in conscious man. Respir Physiol 1975; 23: 181-189.

25. Honda Y, Watababe S, Hashizume I, et al. Hypoxic chemosensitivity in asthmatic patients two decades after carotid body resection. J Appl Physiol 1979; 46: 632-638.

26. Armitage P, Berry G. In: Statistical Methods in Medical Search. Oxford, Blackwell Scientific Publishers, 1987; pp. 296-312.

27. Berger AJ, Mitchell RA, Severinghaus JW. Regulation of respiration. N Engl J Med 1977; 297: 194-201.

28. White DP, Douglas NJ, Pickett CK, Zwillich CW, Weil JV. Sleep deprivation and control of ventilation. Am Rev Respir Dis 1983; 128: 984-986.
29. Garcia-Rio F, Pino-Garcia JM, Racionero MA, et al. Long-term within-subject variability of inspiratory neural drive response to hypoxia. Chest 1998; 114: 521-525.

30. Fewell JE, Konduri GG. Repeated exposure to rapidly developing hypoxemia influences the interaction between oxygen and carbon dioxide in initiating arousal from sleep in lambs. Pediatr Res 1988; 24: 28-33.

31. Weil JV. Ventilatory responses to $\mathrm{CO}_{2}$ and hypoxia after sustained hypoxia in awake cats. J Appl Physiol 1994; 76: 2251-2252.

32. Kunitomo F, Kimura H, Tatsumi K, et al. Abnormal breathing during sleep and chemical control of breathing during wakefulness in patients with sleep apnea syndrome. Am Rev Respir Dis 1989; 139: 164 169.

33. Bayadi SF, Millman RP, Tishler PV, et al. A family study of sleep apnea: anatomic and physiologic interaction. Chest 1990; 98: 554-559. 